ORIGINAL ARTICLE

\title{
Trends and Determinants of Small Birth Weight in Ethiopia: Further Analysis of Ethiopian Demographic and Health Surveys
}

\author{
Ayantu Kebede', Alemi Kebede ${ }^{2}$, Sena Belina ${ }^{3}$, Yonas Biratu ${ }^{3}$
}

\section{OPEN ACCESS}

Citation: Kebede A, Kebede A, Belina S, Biratu Y. Trends and Determinants of Small Birth Weight in Ethiopia: Further analysis of Ethiopian Demographic and Health Surveys. Ethiop J Health Sci. 2021;31

(2):299.

doi:http://dx.doi.org/10.4314/ejhs.v31i2.13

Received: August 29, 2020

Accepted: August 31, 2020

Published: March 1, 2021

Copyright: (C) 2021 Ayantu Kebede Olika, et al. This is an open access article distributed under the terms of the Creative Commons Attribution License, which permits unrestricted use, distribution, and reproduction in any medium, provided the original author and source are credited. Funding: Nil

Competing Interests: The authors declare that this manuscript was approved by all authors in its form and that no competing interest exists.

Affiliation and Correspondence:

${ }^{1}$ Jimma University, Institute of Health, Faculty of Public Health, Department of Epidemiology

${ }^{2}$ Jimma University, Institute of Health, Faculty of Public Health, Population and Family Health Department

${ }^{2}$ Jimma University, Institute of Health, Faculty of Health Sciences, School of Nursing and Midwifery *Email: ayukebede2013@gmail.com

\begin{abstract}
BACKGROUND: Globally, Low Birth Weight (LBW) prevalence is estimated to be $14.6 \%$. It is a major cause of neonatal mortality in developing countries including Ethiopia. Despite extensive institution-based studies in Ethiopia, there is no comprehensive study using countrywide data. Thus, this study aimed to investigate trends and determinants of Small Birth Weight (SBW) among under-five children in Ethiopia.

METHODS: Under-five children data from 2000, 2005, 2011, and 2016 Ethiopian Demographic and Health Surveys (EDHS) were used. However, only 2787 children were weighed at birth and used for analysis in this study. Descriptive statistics and the logistic regression model were used to determine trends and determinants of $S B W$ respectively.

RESULTS: The prevalence of SBW increased from $7.0 \%(95 \% \mathrm{CI}$; 3.1-10.0) to 13.2\% (95\% CI; 11.4-15.0) between 2000 and 2016. The odds of $S B W$ increased by being a female child (AOR 1.50; 95\% CI [1.07-2.09]), mother's with partner occupation of agriculture (AOR 1.54; 95\% CI [1.05-2.26]) and mothers who did not know their partner's occupation (AOR 7.35; 95\% CI [1.9627.48]). However, infants born to mothers with primary (AOR 0.43; 95\% CI [0.29-0.65]), secondary (AOR 0.30; 95\% CI [0.16-0.55]) and higher (AOR 0.55; 95\% CI [0.31-0.97]) educational status versus no education and grandmultiparous mothers (OR 0.39; 95\% CI [0.19-0.78]) versus primiparous had lower odds of $S B W$.

CONCLUSION: In Ethiopia, during the survey period, there was an increment in prevalence of $S B W$, and maternal related factors were significant determinants. Therefore, empowering mothers through education and improving the socioeconomic status of the household can be one strategy to reduce $S B W$.
\end{abstract}

KEYWORDS: Low Birth Weight; Small Birth Weight; Trends; Determinants; EDHS; Ethiopia

\section{INTRODUCTION}

Low Birth Weight (LBW) is defined as weight at birth of less than 2,500 grams (5.5 pounds). At birth, the weight of the baby can be low either due to preterm birth or fetal restricted intrauterine growth $(1,2)$. 
A baby's birth weight can be affected by the mother's fetal growth, her diet from birth to pregnancy, and her body composition at conception. Mothers in deprived socio-economic conditions frequently have LBW infants which resulted from prolonged maternal malnutrition, infections, pregnancy complications, and physically demanding work during pregnancy (3-5).

LBW can predict the child's health throughout life and may result in a wide range of chronic diseases in future life such as ischemic heart disease, stroke, hypertension, diabetes, metabolic syndrome, malignancies, dementia, osteoarthritis, and poor cognitive development (6-9). Besides, it can also leads to reduced school performance and behavior $(10,11)$.

Globally, in 2015 an estimated 20.5 million live births were LBW with a prevalence of $14.6 \%$. However, a considerable variation was observed across regions and within countries on the prevalence, and $91 \%$ of the number is contributed by low- and middle-income countries, mainly Southern Asia (48\%) and subSaharan Africa $(24 \%)(12,13)$.

LBW can be caused by both direct factors related to pregnancy complications and indirect factors such as economic development (2). Studies conducted before reported that maternal age, maternal education, race, occupation, maternal weight and height, sex of the neonate, parity, smoking, inadequate antenatal care, and other factors are related to $\operatorname{LBW}(6,7,14,15)$.

LBW is a key indicator of progress towards global nutrition target achievement set by WHO to reduce LBW by $30 \%$ in 2025 . Therefore, monitoring LBW trend is an essential component of the Global Nutrition Monitoring Framework approved by member states at the World Health Assembly (WHA) in 2015 $(16,17)$. Although some progress was achieved between 2000 and 2015, more than doubling the progress is required to meet the target (12).

In Ethiopia, including the national survey, there is variation in prevalence of LBW between $9.9 \%$ to $28.3 \%(18-21)$. However, majority of the studies conducted were facility-based and no study reported about trends of LBW from nationally representative data. Thus, this study planned to investigate trends and determinants of small birth weight among under-five children in Ethiopia from nationally representative data. So, the finding of the study will be able to provide effective health policies to reduce infant mortality and change the directions of interventions.

\section{METHODS AND MATERIALS}

Ethiopian Demographic and Health Survey (EDHS) is a nationally representative crosssectional survey conducted every five years. In Ethiopia, the first Demographic and Health Survey (DHS) was conducted in 2000 and consequently, in 2005, 2011, and 2016. In the survey, a stratified, two-stage cluster design was used to select a sample. Each region was stratified into urban and rural areas. In the first stage, samples of Enumeration Areas (EAs) were selected independently in each sampling stratum with probability proportional to EA size. In the second stage of selection, households per cluster were selected. Details of sampling design have been mentioned elsewhere $(22,23)$.

Different sets of validated questionnaires containing different unit of analysis were used to collect information from different levels. Those questionnaires were eventually converted into different datasets. In this study, childrecode dataset which contained information about all children who born in the previous five years preceding the survey was used. During the foursurvey period from the total births recorded, only 2787 children were weighed at birth and used for analysis in this study. The 2000, 2005, 2011, and 2016 EDHS data were used for trend analysis and the recent, 2016, EDHS data was used for determinants study. These data was obtained from the DHS data website at www.dhsprogram.com after a written request explaining the purpose of the study was communicated.

The following operational definitions are used for this study.

Outcome variable: In this study, birth weight of the infant was the outcome variable and classified into normal if weight is greater than or equal to 2500 grams, and SBW if below 2500 grams.

Explanatory variables: The explanatory variables included in the study were selected 
based on epidemiological information, prior studies, a review of the relevant published demographic studies, and the available information in the DHS datasets $(7,21,24)$. The included variables were categorized into three: maternal obstetric factors, child factors, sociodemographic and economic factors.

Maternal obstetric factors include maternal age at first pregnancy, number of antenatal visits, history of taking iron supplements during pregnancy, parity, and history of pregnancy termination. The child factors include the child's sex, birth order, and birth interval. The sociodemographic and economic factors included maternal education and occupation, partner education and occupation, wealth index, place of residence, and region.

Maternal age at first pregnancy was categorized into four different age groups: $<20$ years, 20-29 years, $30-34$ years, and $\geq 35$ years. On EDHS, maternal and partner occupation was grouped into did not work, professional/technical/managerial, clerical, sales, agricultural, services, skilled manual, unskilled manual, others and don't know. However, in this study, we created four categories by merging professional/technical/managerial, clerical, sales, services, skilled manual, unskilled manual, and others into working (paid) group; did not work, agricultural, and don't know.

Wealth index was a composite indicator of a household's economic status which was used by DHS surveys globally (25). EDHS categorized wealth index into five different wealth quintiles. However, in this study, it was regrouped into three: poor (poorest and poor), middle (middle), and rich (richer and richest).

Parity was derived from total children ever born to the mother and categorized into (i) primiparous, (ii) multiparous (2-5), and (iii) grand multiparous $(>5)$.

The number of Antenatal Care (ANC) visits was a continuous variable and categorized based on the minimum WHO antenatal visit recommendation: No ANC visit, 1-4 visits, and more than 4 visits.

Maternal history of taking iron supplements during pregnancy was derived from the number of days a mother took the pills and categorized into "Yes", if she took at least for one day, and
"No" if no iron supplement was used during pregnancy.

Birth order was categorized into three categories: (i) first, (ii) second or third, and (iii) fourth and above. Birth interval was categorized into (i) no birth interval for primiparous mother and (ii) less than 24 months and (iii) greater than or equal to 24 months for multiparous mother.

Statistical analysis: Before any statistical analysis, standard EDHS sample weight was applied on the data to account for the unequal probability of selection in the sample and nonresponse. The weighting variable used was women's individual sample weight since the study unit of analysis was women. Descriptive analysis and line graphs were performed to examine trends of SBW. Due to their known high risk of SBW, multiple births were excluded from the analysis. Region, partner education, and history of taking iron supplements during pregnancy were excluded from determinant analysis due to small cases per cell. Backward stepwise regression method was used for model building. To identify candidate variables, bivariate logistic regression at $\mathrm{p}$-value $<0.05$ was considered, and those variables significant on bivariate analysis were further examined using multiple logistic regression. $\mathrm{P}$-value $<0.05$ and confidence interval were used to declare the significance of the variable. Model fitness was checked by Hosmer and Lemeshow test, and the result $(\mathrm{P}$ value $=0.447)$ indicated that the model is a good fit. The statistical analysis was conducted by using IBM SPSS statistics version 20. All figures and tables in the report depict weighted percentages.

Ethics: Ethical clearance for the EDHS was provided by the Ethiopia Health and Nutrition Research Institute (EHNRI) Review Board, the National Research Ethics Review Committee (NRERC) at the Ministry of Science and Technology, the Institutional Review Board of ICF International, and the United States Centers for Disease Control and Prevention (CDC). For this specific analysis, the data was requested; the analysis was approved and permitted.

\section{RESULTS}

Population characteristics: During the four survey periods, a total of 46,318 births were 
recorded in Ethiopia. Five years prior to each survey in 2000, 2005, 2011, and 2016; 12, 260, $11,163,11,872$ and 11,023 live births was born respectively. From the total births recorded, only 2787 children was weighed at birth, and information about birth weight was obtained either from maternal recall or health card. Based on the source of birth weight information, only $29(0.2 \%)$ in $2000,49(0.4 \%)$ in $2005,52(0.4 \%)$ in 2011 and $109(1.0 \%)$ in 2016 was obtained from written card.

Table 1: Trends of Small birth Weight among under-five children in Ethiopia by socio-demographic and economic characteristics: 2000-2016 EDHS.

\begin{tabular}{|c|c|c|c|c|}
\hline \multirow[t]{3}{*}{ Variables } & \multicolumn{4}{|c|}{ Trends of SBW* } \\
\hline & 2000 & 2005 & 2011 & 2016 \\
\hline & $\%$ & $\%$ & $\%$ & $\%$ \\
\hline \multicolumn{5}{|l|}{ Region } \\
\hline Tigray & 5.0 & 0 & 9.8 & 7.6 \\
\hline Afar & 0 & 0 & 20.0 & 28.6 \\
\hline Amhara & 5.3 & 2.7 & 11.6 & 22.4 \\
\hline Oromia & 10.0 & 20.2 & 12.2 & 13.1 \\
\hline Somali & 10.0 & 15.4 & 13.0 & 11.5 \\
\hline Benishangul Gumuz & 0 & 0 & 12.5 & 11.5 \\
\hline $\mathrm{SNNPR}^{\dagger}$ & 0 & 20.5 & 6.3 & 13.2 \\
\hline Gambella & 0 & 20.0 & 11.1 & 11.1 \\
\hline Harari & 0 & 0 & 12.5 & 0 \\
\hline Addis Ababa & 9.9 & 13.2 & 11.5 & 11.5 \\
\hline Dire Dawa & 9.1 & 0 & 14.3 & 9.5 \\
\hline \multicolumn{5}{|c|}{ Type of place of residence } \\
\hline Urban & 8.1 & 10.2 & 9.0 & 10.8 \\
\hline Rural & 2.0 & 22.7 & 17.3 & 15.4 \\
\hline \multicolumn{5}{|l|}{ Wealth index } \\
\hline Poor & NA & 12.4 & 11.2 & 15.8 \\
\hline Middle & NA & 20.9 & 9.6 & 17.2 \\
\hline Rich & NA & 12.9 & 10.6 & 11.7 \\
\hline \multicolumn{5}{|l|}{ Maternal education } \\
\hline No education & 11.1 & 27.7 & 13.5 & 18.2 \\
\hline primary & 7.0 & 18.9 & 8.2 & 11.0 \\
\hline Secondary & 6.0 & 7.8 & 11.4 & 7.8 \\
\hline Higher & 0 & 3.7 & 13.0 & 15.3 \\
\hline \multicolumn{5}{|l|}{ Maternal occupation } \\
\hline Did not work & 6.9 & 14.0 & 12.7 & 13.3 \\
\hline Working (paid) & 3.8 & 7.5 & 12.2 & 11.2 \\
\hline Agriculture & 9.2 & 17.4 & 3.8 & 20.2 \\
\hline \multicolumn{5}{|l|}{ Partner education } \\
\hline No education & 10.0 & 24.3 & 16.9 & 18.3 \\
\hline Primary & 10.3 & 22.9 & 13.1 & 15.3 \\
\hline Secondary & 3.7 & 6.3 & 5.8 & 8.6 \\
\hline Higher & 4.7 & 10.2 & 10.7 & 11.2 \\
\hline \multicolumn{5}{|l|}{ Partner occupation } \\
\hline Did not work & 0 & 12.0 & 13.2 & 14.9 \\
\hline Working (paid) & 5.1 & 10.5 & 12.1 & 10.9 \\
\hline Agriculture & 9.1 & 16.4 & 10.9 & 17.3 \\
\hline Don't know & 0 & 0 & 0 & 40.0 \\
\hline
\end{tabular}

*SBW: Small Birth Weight: †SNNPR: Southern Nation, Nationalities and People Representatives. NA: The data for the wealth index was not available 
Socio-demographic and Economic characteristics: Variations in the occurrence of SBW were observed among nine regions and two administrative towns of Ethiopia. Across regions, there is an increment in the number of cases from time to time. In Afar, Benishangul Gumuz, and Harari regions, there is no reported SBW baby in 2000 and 2005 EDHS. During 2016, relatively more cases were reported in all regions and the three top regions with SBW were Afar (28.6\%), Amhara (22.4\%), and Southern Nation and Nationalities (13.2\%) (Table1).
Though there is variation in the number of SBW across maternal educational status, SBW most commonly occurs among mothers who did not attend any formal education. During 2000, 2005, 2011, and 2016 EDHS, respectively $11.1 \%$, $27.7 \%, 13.5 \%$, and $18.2 \%$ of SBW were born to mothers who did not attend any education. Similarly, $9.2 \%, 17.4 \%$, and $20.2 \%$ of SBW babies were reported from mothers whose occupation was agriculture in 2000,2005 , and 2016 EDHS respectively (Table 1).

Table 2: Trends of Small birth Weight among under-five children in Ethiopia by Maternal Obstetrics and child-related characteristics: 2000-2016 EDHS.

\begin{tabular}{|c|c|c|c|c|}
\hline \multirow[t]{2}{*}{ Variables } & \multicolumn{4}{|c|}{ Trends of SBW } \\
\hline & 2000 & 2005 & 2011 & 2016 \\
\hline Maternal obstetric characterstics & $\%$ & $\%$ & $\%$ & $\%$ \\
\hline \multicolumn{5}{|l|}{ Number of ANC ${ }^{\ddagger}$ visits } \\
\hline No ANC visit & 4.3 & 4.9 & 10.1 & 6.9 \\
\hline $1-4$ visit & 10.6 & 13.3 & 11.4 & 12.6 \\
\hline More than 4 visit & 9.3 & 14.0 & 11.1 & 12.7 \\
\hline \multicolumn{5}{|l|}{ Age at first birth } \\
\hline$<20$ & 8.3 & 13.8 & 8.3 & 14.0 \\
\hline $20-29$ & 5.6 & 12.8 & 14.9 & 12.6 \\
\hline $30-34$ & 0 & 0 & 0 & 12.0 \\
\hline $35-40$ & 0 & 0 & 0 & 16.7 \\
\hline \multicolumn{5}{|c|}{ Took iron supplementation during pregnancy } \\
\hline Yes & 8.7 & 11.5 & 8.5 & 12.9 \\
\hline No & 0 & 0 & 100 & 3.8 \\
\hline \multicolumn{5}{|c|}{ Ever had terminated pregnancy history } \\
\hline No & 7.7 & 12.5 & 10.7 & 13.6 \\
\hline Yes & 4.1 & 19.6 & 12.1 & 6.3 \\
\hline \multicolumn{5}{|l|}{ Parity } \\
\hline Primiparous & 5.3 & 4.5 & 10.5 & 9.8 \\
\hline Multiparous & 4.3 & 14.1 & 12.2 & 16.3 \\
\hline Grandmultiparous & 13.2 & 15.9 & 9.5 & 7.1 \\
\hline \multicolumn{5}{|l|}{ Child-related characteristics } \\
\hline \multicolumn{5}{|l|}{ Sex of child } \\
\hline Male & 6.1 & 9.6 & 9.7 & 10.8 \\
\hline Female & 7.7 & 17.6 & 11.8 & 15.6 \\
\hline \multicolumn{5}{|l|}{ Birth order } \\
\hline First & 3.1 & 7.7 & 9.2 & 11.5 \\
\hline Second/third & 5.5 & 16.8 & 14.9 & 13.6 \\
\hline Fourth and above & 9.5 & 14.1 & 8.6 & 14.9 \\
\hline \multicolumn{5}{|l|}{ Birth interval } \\
\hline$<24$ months & 6.2 & 8.9 & 12.3 & 18.0 \\
\hline$\geq 24$ months & 8.3 & 17.1 & 10.8 & 13.6 \\
\hline
\end{tabular}

DOI: http://dx.doi.org/10.4314/ejhs.v31i2.13 
Partner educational status and occupation are the other important variables for SBW. According to EDHS 2005, 2011 and 2016 SBW is more common among mothers whose partners did not attend any education, and there is no trend between the prevalence of SBW and educational status. Regarding partner occupation, in 2000 and $2005 ; 9.1 \%$ and $16.4 \%$ of SBW babies respectively born to mothers whose partners' occupation was agriculture. However, surprisingly in $2016,40 \%$ of SBW babies were born to mothers who did not know their partners' occupation (Table 1).

Maternal obstetrics and child characteristics: Prevalence of SBW increased from time to time based on maternal age at first birth, and the prevalence is more common among youngsters. In 2016, $14.9 \%$ of SBW occurred among mothers in the age group of 20 to 29 years (Table 2).

Parity might also affect the outcome of pregnancy. Based on 2000 and 2005 EDHS, $13.2 \%$ and $15.9 \%$ of SBW babies born to grand multiparous mothers respectively. However, in 2011 and 2016, SBW was more common among multiparous mothers (Table 2).

According to EDHS 2000 and 2016, 7.7\% and $13.6 \%$ of SBW babies born to mothers who had no experience of pregnancy termination respectively. However, during 2005 and 2011 EDHS, it was more common among those who had history of pregnancy termination (Table 2).

During 2000 and 2016, across birth order, there was an increment in the prevalence of SBW. In 2000, 9.5\% and in 2016, $14.9 \%$ of SBW occurred among children whose birth order was fourth or above. Yet, in 2005 and 2011, the prevalence of SBW was more common among children in second or third birth order (Table 2).

Concerning birth intervals, in 2000 and 2005 respectively, $8.3 \%$ and $17.1 \%$ of those whose birth intervals were greater than or equal to 24 months weigh low compared to those whose birth intervals were less than 24 months $(6.2 \%)$ and $(8.9 \%)$. However, during the 2011 and 2016 survey period, SBW was greater in those with birth intervals less than 24 months compared to those whose birth intervals were greater than or equal to 24 months (Table 2).
Trends of small birth weight: The number of SBW infants increased from 22 in 2000 to 198 in 2016. The prevalences of SBW were $7.0 \%$ (95\% CI; 3.1-10.0), 13.5\% (95\% CI; 11.4-15.0), $10.8 \%$ (95\% CI; 8.5-13.8), and $13.2 \%(95 \% \mathrm{CI}$; 11.4-15.0) in 2000, 2005, 2011 and 2016 respectively (Figure 1).

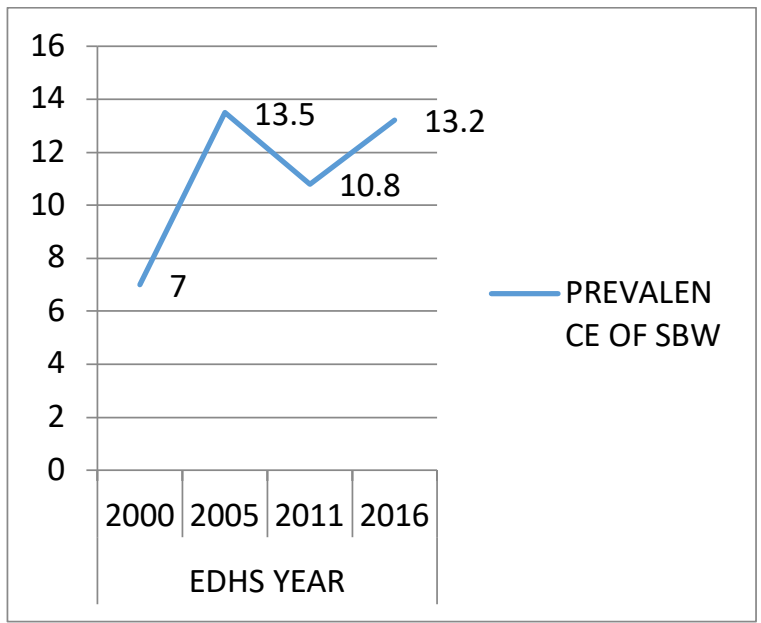

Figure 1: Trends of Small Birth Weight among under five children in Ethiopia: 2000-2016 EDHS

Determinants of Small Birth Weight: Among different variables assessed, educational status of the mother, partner occupation, parity, and sex of the infant remained significant determinants of Small Birth Weight.

Mothers who attended primary (AOR 0.43;95\% CI[0.29-0.65]), secondary (AOR 0.30; 95\% CI [0.16-0.55]) and higher (AOR 0.55; 95\% CI [0.31-0.97]) educational level were less likely to have SBW infants compared to those who did not attend any education. Mothers whose partners' occupation was agriculture (AOR 1.54; 95\% CI [1.05-2.26]) and who did not know their partners' occupation (AOR 7.35; 95\% CI [1.96-27.48]) were more likely to deliver SBW infants compared to mothers whose partners participated in paid work. The odds of having SBW infant were less likely in grand multiparous mothers (AOR 0.39; 95\% CI [0.19-0.78]) compared to primiparous mothers. Female infants were more likely (AOR 1.50; 95\% CI [1.07-2.09]) to be SBW compared to male infants (Table 3 ). 
Table 3: Bivariate and Multiple Logistic Regression model showing determinants of Small Birth Weight in Ethiopia: EDHS 2016.

\begin{tabular}{|c|c|c|c|c|c|}
\hline \multirow[t]{2}{*}{ Factors } & \multicolumn{2}{|c|}{ Birth weight } & \multirow[t]{2}{*}{ COR } & \multirow[t]{2}{*}{ P-value } & \multirow[t]{2}{*}{ AOR } \\
\hline & $<2500 \mathrm{~g}$ & $\geq 2500 \mathrm{~g}$ & & & \\
\hline \multicolumn{6}{|c|}{ Type of place of residence } \\
\hline Urban & 67 & 639 & 1.00 & $0.001^{*}$ & 1.00 \\
\hline Rural & 113 & 637 & $1.70(1.23-2.35)$ & & \\
\hline Wealth index & & & & $0.028^{*}$ & \\
\hline Poor & 39 & 211 & $1.53(1.03-2.27)$ & & \\
\hline Middle & 32 & 169 & $1.58(1.03-2.42)^{*}$ & & \\
\hline Rich & 108 & 896 & 1.00 & & 1.00 \\
\hline Mothers education & & & & $0.000 *$ & \\
\hline No education & 76 & 349 & 1.00 & & 1.00 \\
\hline Primary & 58 & 494 & $0.54(0.37-0.78)$ & & $0.43(0.29-0.65)^{* *}$ \\
\hline Secondary & 18 & 244 & $0.33(0.19-0.57)$ & & $0.30(0.16-0.55)^{* *}$ \\
\hline Higher & 28 & 189 & $0.68(0.42-1.08)$ & & $0.55(0.31-0.97)^{* *}$ \\
\hline Mother occupation & & & & $0.053 *$ & \\
\hline Not working & 84 & 574 & 1.00 & & 1.00 \\
\hline Working & 68 & 571 & $0.81(0.58-1.14)$ & & \\
\hline Agriculture & 28 & 131 & $1.50(0.94-2.38)$ & & \\
\hline Partner education & & & & 0.001 & \\
\hline No education & 50 & 231 & 1.00 & & \\
\hline Primary & 71 & 412 & $0.79(0.53-1.17)$ & & \\
\hline Secondary & 25 & 270 & $0.42(0.25-0.70)$ & & \\
\hline Higher & 26 & 275 & $0.43(0.26-0.71)$ & & \\
\hline Don't know & 0 & 5 & $0.23(0.01-11.46)$ & & \\
\hline \multicolumn{6}{|l|}{ Partner occupation } \\
\hline Working & 84 & 743 & 1.00 & & 1.00 \\
\hline Not working & 7 & 62 & $0.94(0.41-2.17)$ & $0.000 *$ & $0.83(0.35-1.97)$ \\
\hline Agriculture & 77 & 382 & $1.77(1.27-2.47)$ & & $1.54(1.05-2.26)^{* *}$ \\
\hline Don't know & 4 & 6 & $5.79(1.61-20.80)$ & & $7.35(1.96-27.48)^{* *}$ \\
\hline Sex of the infant & & & & $0.025 *$ & \\
\hline Male & 78 & 667 & 1.00 & & 1.00 \\
\hline Female & 102 & 609 & $1.43(1.04-1.95)$ & & $1.50(1.07-2.09)^{* *}$ \\
\hline \multicolumn{6}{|l|}{ Birth order } \\
\hline First & 62 & 490 & 1.00 & 0.344 & \\
\hline Second/third & 61 & 451 & $1.07(0.74-1.56)$ & & \\
\hline Fourth or more & 56 & 335 & $1.31(0.89-1.93)$ & & \\
\hline Birth interval & & & & 0.108 & \\
\hline No birth interval & 62 & 490 & $(0.65-1.29)$ & & \\
\hline$<24$ months & 22 & 99 & $1.59(0.96-2.65)$ & & \\
\hline$\geq 24$ months & 96 & 688 & 1.00 & & \\
\hline
\end{tabular}


Table 3. Continued...

\begin{tabular}{|c|c|c|c|c|c|}
\hline \multicolumn{4}{|l|}{ Age at first birth } & \multirow[t]{2}{*}{0.330} & \\
\hline $11-19$ & 97 & 600 & 1.00 & & \\
\hline $20-29$ & 78 & 628 & $0.77(0.56-1.06)$ & & \\
\hline $30-34$ & 4 & 43 & $0.53(0.18-1.57)$ & & \\
\hline $35-40$ & 1 & 5 & $0.71(0.04-11.90)$ & & \\
\hline \multicolumn{4}{|c|}{ Ever had terminated pregnancy history } & $0.055^{*}$ & \\
\hline Yes & 5 & 82 & $0.45(0.18-1.09)$ & & $0.38(0.14-1.01)$ \\
\hline No & 174 & 1194 & 1.00 & & 1.00 \\
\hline \multicolumn{6}{|l|}{ Parity } \\
\hline Primiparous & 44 & 407 & 1.00 & & 1.00 \\
\hline Multiparous & 121 & 696 & $1.61(1.12-2.32)$ & $0.003 *$ & $1.40(0.93-2.11)$ \\
\hline Grandmultipara & 14 & 172 & $0.75(0.40-1.42)$ & & $0.39(0.19-0.78)^{* *}$ \\
\hline ANC visit & & & & 0.519 & \\
\hline No any visit & 5 & 63 & $0.59(0.23-1.53)$ & & \\
\hline 1 - 4 visit & 78 & 571 & $1.02(0.72-1.46)$ & & \\
\hline More than 4 visit & 61 & 458 & 1.00 & & \\
\hline
\end{tabular}

\section{DISCUSSION}

LBW is a major public health problem worldwide especially in developing countries including Ethiopia. It is a major contributor to adverse pregnancy outcomes $(6,15)$. Therefore, this study aimed to determine trends of SBW and its determinants in Ethiopia using EDHS data. Based on the study finding, there is an increment in the number of SBW from 2000 to 2016 EDHS, and educational status of the mother, partner occupation, parity, and sex of the infant were determinants of SBW.

In Ethiopia, the prevalence of SBW was increasing except slight reduction from 2005 to 2011. This national prevalence of SBW in 2016 was below that of Bangladesh $(20 \%)(26)$. This might be due to the difference in the survey period considered for calculating the prevalence. In the case of Ethiopia, a sample of live births born five years preceding the survey period was considered. However, in Bangladesh, only live births in the last two years preceding the survey were included. Also, there is a difference in the number of cases for whom birth weight data were available. In Ethiopia, birth weight data were available only for 1501 cases while $78.1 \%$ of cases were not weighed at birth. However, in
Bangladesh data was available for 2319 cases and on the dataset, $71 \%$ of newborns show no birth weight information.

Educational status was one of SBW determinants. In this study, mothers who attended primary, secondary, and higher educational levels less likely deliver SBW babies compared to illiterate mothers. This finding is consistent with a study conducted in Cambodia using DHS data, further analysis of 2011 EDHS, and cohort studies conducted in southern Ethiopia (27-29). Having a higher educational level had a protective effect in a way that educated women have a higher possibility of making household decisions and have access to a nutritious diet during pregnancy that would, in turn, improve their body's composition which influences infant weight. Also, they can comply with nutritional counseling during ANC visits since they may be economically stable than women who did not attend any formal education.

Besides, in developing countries deprivation of socio-economic status including educational status, occupation and others are risk factors for SBW $(2,7,30)$. This finding implies that uneducated mothers are the most disadvantageous group both in exposure to 
information and ANC attendance which is crucial for being informed about different maternal cares during pregnancy and improved neonatal outcomes $(31,32)$.

In this study, partner occupation is the other determinants for SBW. Mothers who do not know their partners' occupation and those whose partner occupation was agriculture were more likely to experience SBW. Evidence suggests that individual-level socioeconomic status (SES) is a risk factor for Small for Gestation Age (SGA) births, and low SES influence the risk of SGA birth due to residential, lifestyle, or occupational-related exposure to harmful agents $(33,34)$. Available evidence indicates the mechanisms by which partner occupational exposure affects birth outcomes. The first is partner exposure leads to maternal exposure, and the effects will happen. The second mechanism is partner exposure leads to alteration in a germ cell line that leads to either increased infertility or abnormality in conception (35). Among the different effects of toxic chemicals, lead exposure is associated with infertility, stillbirths, and spontaneous abortions (36). However, from this specific study, we cannot be able to assess occupational-related toxic chemical exposure.

Newborn sex had gestational ageindependent effects on birth weight, and female neonates had lower average birth weights than male neonates at each specific week of gestation $(37,38)$. Similarly, in this study, female infants were more likely to experience SBW than male infants. This finding is consistent with studies conducted in Northern Ethiopia, Sidama Zone, and a systematic review conducted in Ethiopia $(14,29,39)$. This might be due to the effect of the Y chromosome on the weight of the male fetus which needs further genetic evaluation of the pregnant mothers' population (40). Besides, it might also be due to greater lean body mass and less body fat seen in male newborns than in females, possibly due to the effects of fetal testosterone production (41). However, this needs biological investigation to identify the effects of neonate sex on birth weight.

Maternal parity is one of the well-known predictors of infant birth weight; the lowest birth weights were found in infants born to primiparous women (42). Also, in this study, parity was associated with birth weight; grand multiparous mothers were less likely to deliver SBW babies compared to primiparous mothers. This might be due to higher risks of obstetric complications such as gestational diabetes and gestational hypertensive disorders associated with grand multiparity which lead to fetal macrosomia rather than SBW $(43,44)$.

Generally, in Ethiopia, SBW prevalence is increasing and maternal education, partner occupation, parity, and sex of the baby were determinants for SBW. Therefore, there is a need to empower mothers through education which might indirectly contribute to the reduction of SBW by improving household economic status.

As a limitation, only factors that were found on the data were retrieved and the analysis was not controlled for other genetic or biological factors. Thus, given that the etiology of SBW is complex, further research is required to address the interaction of genetic or biological factors with social and environmental factors.

In addition, possible biases like social desirability bias due to sensitiveness of the issues, recall bias due to longer recall time and measurement bias because of obtaining birth weight data from maternal subjective evaluation during the survey might affect the study finding.

\section{REFERENCES}

1. World Health Organization. International Statistical Classification of Diseases and Related Health Problems. 10th ed. Vol. 2. Geneva, Switzerland: World Health Organization; 2010.

2. Kramer MS. Determinants of low birth weight: methodological assessment and meta-analysis. Bull World Health Organ. 1987;65(5):663-737.

3. Miheso A, Gathigi Maina L WAKD and HS. Kenya. Rockville, Maryland, USA; 2015.

4. Sebayang SK, Dibley MJ, Kelly PJ, Shankar A V, Shankar AH. Determinants of low birthweight, small-forgestational-age and preterm birth in 
Lombok , Indonesia: analyses of the birthweight cohort of the SUMMIT trial. Trop Med Int Heal. 2012;17(8):938-50.

5. United Nations Children's Fund and World Health organizations. Low Birthweight: Country, regional and global estimates. UNICEF, New York; 2004.

6. Chen Y, Li G, Ruan Y, Zou L, Wang X, Zhang W. An epidemiological survey on low birth weight infants in China and analysis of outcomes of full-term low birth weight infants. BMC Pregnancy Childbirth. 2013;13(242).

7. IHE R. Determinants and Prevention of Low Birth Weight: A Synopsis of the Evidence. 2008;

8. Barker DJ, Gluckman PD, Godfrey KM, Harding JE, Owens JA RJ. Fetal nutrition and cardiovascular disease in adult life. Lancet. 1993;341((8850).):938-41.

9. Risnes KR, Vatten LJ, Baker JL, Jameson K, Sovio U, Kajantie E, et al. Birthweight and mortality in adulthood: a systematic review and meta-analysis. Int J Epidemiol. 2011;40:647-61.

10. Natalie A. Williams M. Short and long term affects of birth weight and neonatal medical complications on children's emotional and behavioural outcomes. University of Missouri-Columbia; 2008.

11. Islam MM. The Effects of Low Birth Weight on School Performance and Behavioral Outcomes of Elementary School Children in Oman. Oman Med J. 2015;30(4):241-51.

12. Blencowe H, Krasevec J, Onis M De, Black RE, An X, Stevens GA, et al. National , regional, and worldwide estimates of low birthweight in 2015 , with trends from 2000: a systematic analysis. Lancet Glob Heal. 2015;7(7):e849-60.

13. Kim D, Saada A. The Social
Determinants of Infant Mortality and Birth Outcomes in Western Developed Nations: A Cross-Country Systematic Review. Int J Environ Res Public Heal. 2013;10:2296-335.

14. Bililign $\mathrm{N}$, Legesse $\mathrm{M}$, Akibu $\mathrm{M}$. iMedPub Journals A Review of Low Birth Weight in Ethiopia: SocioDemographic and Obstetric Risk Factors Abstract Magnitude of low birth weight. Glob J Res Rev. 2018;5(1:4):1-5.

15. Mahumud RA, Sultana M, Sarker AR. Distribution and Determinants of Low Birth Weight in Developing Countries. $J$ Prev Med Public Heal. 2017;50:18-28.

16. WHO. Comprehensive Implementation plan on Maternal, Infant and Young Child Nutrition. Geneva, Switzerland; 2014.

17. World Health Organization. Global targets 2025. To improve maternal, infant and young child nutrition (www.who.int/nutrition/topics/nutrition globaltargets 2025 .

18. Teklehaimanot $\mathrm{N}$, Hailu $\mathrm{T}$, Assefa $\mathrm{H}$. Prevalence and factors associated with low birth weight in Axum and Laelay Maichew Districts, North Ethiopia: A comparative cross sectional study. Int $J$ Nutr Food Sci. 2014;3(6):560-6.

19. Lake EA, Fite RO. Low Birth Weight and Its Associated Factors among Newborns Delivered at Wolaita Sodo University Teaching and Referral Hospital , Southern Ethiopia , 2018. 2019;2019.

20. Wado YD, Afework MF HM. Effects of maternal pregnancy intention, depressive symptoms and social support on risk of Low Birth Weight: A prospective study from southwestern Ethiopia. PLoS One. 2014;9(e96304).

21. Endalamaw A, Engeda EH, Ekubagewargies DT, Belay GM, Tefera 
MA. Low birth weight and its associated factors in Ethiopia: A systematic review and meta-analysis. Ital $J$ Pediatr. 2018;44(141):1-12.

22. Central Statistical Agency [Ethiopia] and ICF International. Ethiopia Demographic and Health Survey 2011. Addis Ababa, Ethiopia and Calverton,Maryland, USA; 2012.

23. Central Statistical Agency [Ethiopia] and ICF International. Ethiopia Demographic and Health Survey 2016. Addis Ababa, Ethiopia and Calverton,Maryland, USA; 2017.

24. Khanal V, Sauer K, Karkee R, Zhao Y. Factors associated with small size at birth in Nepal: further analysis of Nepal Demographic and Health Survey .2011. BMC Pregnancy Childbirth . 2014;

25. Rutstein SO JK. The DHS Wealth Index. Calverton, Maryland; 2004.

26. Khan JR, Islam M, Awan N, Muurlink O. Analysis of low birth weight and its covariants in Bangladesh based on a subsample from nationally representative survey. BMC Pediatr. 2018;18(100):1-9.

27. Chhea C, Ir P, Id HS. Low birth weight of institutional births in Cambodia: Analysis of the Demographic and Health Surveys 2010-2014. PLoS One. 2018;13(11):1-16.

28. Taddese A, Alemu $\mathrm{T}$, Umeta $\mathrm{M}$. Prevalence and Predictors of "Small Size "Babies in Ethiopia: In- depth Analysis of the Ethiopian Demographic and Health Survey , 2011. 2011;

29. Gebremedhin S, Enquselassie F, Umeta M. Independent and Joint Effects of Prenatal Zinc and Vitamin A Deficiencies on Birthweight in Rural Sidama, Southern Ethiopia: Prospective Cohort Study. PLoS One. 2012;7(12).

30. Muthayya S. Maternal nutrition \& low birth weight - what is really important?
Indian J Med Res. 2009;130:600-608 Maternal.

31. White DE, Fraser-Lee NJ, Tough S NC. The content of prenatal care and its relationship to preterm birth in Alberta, Canada. Heal care women Int. 2006;27(6):777-92.

32. Panaretto KS, Lee HM, Mitchell MR, Larkins SL, Manessis V, Buettner PG WD. Impact of a collaborative shared antenatal care program for urban indigenous women: a prospective cohort study. Med J Aust. 2005;182(10):514-9.

33. Parker JD, Schoendorf KC KJ. Association between measures of socioeconomic status and low birth weight, small fof gestational age and premature delivery in the United states. Ann Epidemiol. 1994;4:271-8.

34. Li X, Sundquist J, Sundquist K. Parental occupation and risk of small- forgestational-age births: a nationwide epidemiological study in Sweden. Hum Reprod. 2010;25(4):1044-50.

35. Strobino BR, Kline J SZ. Chemical and physical exposures of parents: effects on human reproduction and offspring. Early Hum Dev. 1978;1:371-99.

36. Savitz DA, Whelan EA KR. Effect of parent's occupational exposures on risk of still birth, preterm delivery, and small for gestational age infants. $\mathrm{Am} J$ Epidemiol. 1989;129:1201-18.

37. Thomas P, Peabody J, Turnier V, Clark RH. A new look at Intrauterine Growth and the Impact of Race, Altitude, and Gender. Pediatrics. 2000;106(2).

38. Kayemba-kay S, Geary MPP, Pringle J, Rodeck $\mathrm{CH}$, Kingdom JCP, Hindmarsh PC. Gender, smoking during pregnancy and gestational age influence cord leptin concentrations in newborn infants. Eur $J$ Endocrinol. 2008;159:217-24.

39. Mengesha HG, Wuneh AD, 
Weldearegawi B, Selvakumar DL. Low birth weight and macrosomia in Tigray, Northern Ethiopia: who are the mothers at risk? BMC Pediatr. 2017;17(144):1-9.

40. Adams KM, Altemus M, Annas GJ, Baschat AAM, Battista LRM E. Obstetrics: Normal and problem pregnancies. 5th ed. Philadelphia: CHURCHILL LIVINGSTONE ELSEVIER.; 2007. 19103-2899 p.

41. Milner RDG GP. Regulation of intra utrine growth. pediatrics and perinatology:The Scientific basis. 2nd editio. Ltd London: Arnold publisher;
1996.

42. Shah PS. Parity and low birth weight and preterm birth: a systematic review and. Acta Obstet Gynecol. 2010;89:862-75.

43. Ashimi AO. Grand multiparity : Obstetric performance in Aminu Kano Teaching Hospital, Kano, Nigeria. 2011;14(1):6-9.

44. Maymon E, Ghezzi F, Shoham-vardi I, Hershkowitz R, Franchi M, Katz M, et al. Peripartum complications in grand multiparous women : para $6-9$ versus. 1998;81:21-5. 